\title{
A Group B Streptococcal Extract Reduces Neutrophil Counts and Induces Neutrophil Aggregation $^{1}$
}

\author{
THOMAS A. OLSON, GERALD W. FISCHER, VAL G. HEMMING, WILLIAM F. O'BRIEN, \\ STEPHEN M. GOLDEN, AND DAVID A. MAYBEE \\ Department of Pediatrics, Uniformed Services University of the Health Sciences, F. Edward Hébert School of \\ Medicine, Bethesda, MD and Walter Reed Army Medical Center, Washington, DC
}

\begin{abstract}
The possibility that group B streptococci (GBS) may induce neonatal neutropenia by promoting neutrophil aggregation and the entrapment of aggregates in the lung was studied in vivo and in vitro utilizing a cell free GBS extract [(GBS)-trichloroacetic acid (TCA)]. The intravenous infusion of the extract into neonatal lambs induced reductions of circulating white blood cells ( 0 time, $3.1 \times 10^{3} / \mathrm{mm}^{3} \pm 0.5$ versus $\left.2.2 \times 10^{3} / \mathrm{mm}^{3} \pm 0.7\right) 5 \mathrm{~min}$ after infusion $(p<0.01)$. At necropsy these lambs had prominent accumulation of polymorphonuclear leukocytes in their pulmonary interstitium. Subsequently, neutrophil aggregation was studied by incubating GBS-TCA in human serum or phosphate-buffered saline with subsequent addition to human polymorphonuclear leukocytes in an aggregometer. GBS-TCA incubated in human serum induced prompt polymorphonuclear leukocyte aggregation (mean $\Delta \mathrm{T} 12.3 \% \pm 2.8$ in human serum versus $\Delta \mathrm{T} 2.5 \% \pm 2.1$ in phosphate-buffered saline, $p<0.001)$. Preincubation of GBS-ICA followed by incubation in human serum with human GBS hyperimmune IgG significantly reduced aggregation (GBS-TCA in serum mean $\triangle \mathrm{T} 14.9 \pm 2.44$ versus $5.42 \pm 1.80, p=0.002$ ). Cell-free GBS products may induce polymorphonuclear leukocyte aggregation in the presence of whole serum. This pnenomenon might contribute to the pulmonary injury experienced by infants with GBS pneumonia and sepsis. (Pediatr Res 21: 326-330, 1987)
\end{abstract}

\section{Abbreviations}

GBS, group B streptococci

PMN, polymorphonuclear leukocyte

GBS-TCA, group B streptococcal trichloroacetic acid extract

PBS, phosphate-buffered saline

GBS-IgG, GBS-TCA exposed to GBS immune globulin

GBS is a major cause of sepsis and meningitis in neonates. Neutropenia is frequently associated with neonatal GBS infections. The cause for the reduction in circulating neutrophils is

Received May 20, 1986; accepted November 13, 1986.

Correspondence Gerald W. Fischer, M.D., Department of Pediatrics, Uniformed Services University of the Health Sciences, 4301 Jones Bridge Road, Bethesda, MD 20814-4799.

Address for reprint requests Thomas A. Olson, MAJ, MC, USA, Department of Pediatrics, Walter Reed Army Medical Center, Washington, DC 20307.

Supported in part by Department of Clinical Investigation, Walter Reed Army Medical Center, Washington, DC 20307.

' Presented in part for Society of Pediatric Research, May 1985 and Interscience Conference on Antimicrobial Agents and Chemotherapy, October 1986. poorly understood. Pulmonary disease, which includes marked infiltration of PMNs into the alveoli and interstitium, is responsible for much of the morbidity associated with GBS infections in the neonate (1). Bacteremia and tissue invasion by live bacteria are important in the pathogenesis of GBS disease. The studies reported in this paper suggest that cell-free GBS antigens (2) may also play a role in neonatal GBS disease. The GBS extract reduced circulating numbers of PMNs and induced PMN sequestration in lamb lungs in vivo (3) and also aggregated human PMNs in an in vitro system. Antibody to GBS prevents PMN aggregation. During sepsis, GBS antigens may induce PMN aggregation and nonspecific entrapment in the pulmonary vasculature contributing to the neutropenia and pulmonary complications of GBS infections.

\section{MATERIALS AND METHODS}

Extract. GBS type III (strain 878) was grown overnight in 3liter batches in Todd-Hewitt broth (Difco Laboratories, Detroit, MI), centrifuged at $2500 \times g$ for $10 \mathrm{~min}$ and the supernatant discarded. The bacterial button was resuspended in $200 \mathrm{ml}$ of $2 \%$ TCA and stirred overnight at $4^{\circ} \mathrm{C}$. The cell button was removed by centrifugation $(2500 \times g$ for $10 \mathrm{~min})$, and 4 volumes of absolute ethanol was added to the supernatant. The mixture was stored overnight at $4^{\circ} \mathrm{C}$ and the fine precipitate removed by centrifugation and lyophilized (The Virtis Company, model 6212-0010, Gardiner, NY) (2). The final extract contained $10 \%$ protein, the remainder was carbohydrate including small amounts of group and type III carbohydrate as determined by capillary precipitation. Chromatographic carbohydrate fingerprints of the extract resembled those of whole GBS cells (2). A Limulus lysate assay was done to rule out endotoxin contamination of the extract.

Lamb studies. Neonatal lambs, less than 7 days of age, of either sex were used. After local xylocaine anesthesia, a no. 5 French Swan-Ganz catheter was placed in the jugular vein and advanced into the pulmonary artery. A carotid artery was also cannulated. Pulmonary and systemic arterial pressures were measured with pressure transducers and blood samples were collected through the indwelling catheters.

All solutions were infused into the lambs' superior vena cava. Each received a bolus injection of GBS-TCA $(1 \mathrm{mg} / \mathrm{kg})$ dissolved in $25 \mathrm{ml}$ of normal saline. Three control lambs were infused only with $25 \mathrm{ml}$ of normal saline. Blood specimens were taken at $0,5,10$, and $20 \mathrm{~min}$ following intravenous infusion (saline was given to replace the volume of blood removed). Total leukocyte counts were performed manually. Twenty minutes after completion of the study the animals were sacrificed by intravenous injection of thiopental. Following necropsy, specimens of lung tissue were fixed, sectioned, and stained with hematoxalin and eosin (3). 
Neutrophil preparation. Peripheral venous blood from healthy adult volunteers or umbilical cord blood from infants was collected into circulated tubes and centrifuged on a Ficoll-Hypaque gradient to concentrate neutrophils. Red blood cells were removed on a dextran sedimentation column followed by treatment with hypotonic saline (4). The neutrophils (PMNs) were suspended in Hanks' balanced salt solution at a concentration of $1 \times 10^{7}$ cells $/ \mathrm{ml}$.

Neutrophil aggregation studies. The induction of aggregation of neutrophils by GBS-TCA was measured with a Sienco Dual Channel Aggregation Meter (Morrison-Sienco Co., Morrison, $\mathrm{CO}$ ). The aggregometer was standardized with a $1: 1$ dilution of cells at $95 \%$ transmission and with undiluted cells at $0 \%$ transmission. The method of Craddock et al. (5) method was utilized to aggregate the cells. Each neutrophil suspension $(0.4 \mathrm{ml})$ was placed in a cuvette with a siliconized stir bar, and equilibrated in the aggregometer at $37.5^{\circ} \mathrm{C}$ at a stir rate of $900 \mathrm{rpm}$.

Test solutions. Experimental solutions were prepared by incubation with serum or PBS in the same manner. After incubation at $37^{\circ} \mathrm{C}$ for $30 \mathrm{~min}$, the test solutions $(0.05 \mathrm{ml})$ were added to neutrophils in the aggregometer and the change in light transmission over 1 min was measured. The change in light transmission $(\Delta \mathrm{T})$ corresponds to aggregation of the cells.

Initial studies. GBS-TCA was incubated in serum for $30 \mathrm{~min}$ prior to addition to PMNs. The final concentrations of the extract in the aggregometer were 0.01 to $1 \mathrm{mg} / \mathrm{ml}$. After the initial dose response studies with adult PMNs, GBS-TCA $(1.0 \mathrm{mg} / \mathrm{ml}$ in serum or PBS) was individually tested with PMNs from eight adult volunteers. Serum alone was added to PMNs as a control. To exclude TCA effect, TCA 2.5 to $25 \%$ was added to PBS and serum before addition to PMNs in the incubator. These cord blood specimens were tested at $1.0 \mathrm{mg} / \mathrm{ml} \mathrm{GBS}$-TCA in serum.

Follow-up studies. Initial studies indicated that GBS-TCA would aggregate PMNs only in the presence of serum. Attempts were made to block aggregation by complement inactivation or by the addition of a GBS immunoglobulin. In these experiments a new source of human serum was utilized as the earlier lot had been depleted. The final extract concentration in these studies was $0.1 \mathrm{mg} / \mathrm{ml}$ as the new serum produced good aggregation curves at lower extract concentrations.

Immunoglobulin. GBS immune globulin (lot 004) was provided by the Sandoz Research Institute, Vienna, Austria. Adult human volunteers were immunized with a pentavalent GBS vaccine, their convalescent plasma pooled, alcohol fractionated, and the resultant IgG was processed by the Swiss Red Cross for intravenous administration (Sandoglobulin). To determine if GBS antibody in this preparation might prevent PMN aggregation, GBS-TCA was incubated with $10 \%$ GBS-immune globulin for $30 \mathrm{~min}$ (GBS-IgG) and added to serum. The mixture was then added to neutrophils in the aggregometer. In addition the inhibitory activity of commercially prepared intravenous $\gamma$-globulin (Sandoglobulin lot 2.370.069.0) was examined.

Complement studies. Human serum was heated at $56^{\circ} \mathrm{C}$ for $30 \mathrm{~min}$ before or after the addition of GBS-TCA. In addition, $20 \mathrm{mM}$ EGTA was added to serum prior to addition of extract. In these experiments GBS-TCA in serum served as a paired control.

Statistical analysis. Data were compared with a paired $t$ test.

\section{RESULTS}

Animal studies. The intravenous infusion of GBS-TCA into 1- to 6-day-old lambs induced significant reductions in the total circulating white blood counts (3). A striking difference was observed in pulmonary histology in the lambs exposed to GBSTCA as compared to controls. The pulmonary septae of control lambs were normal (Fig. 1). Lambs infused with GBS-TCA had widened alveolar septae, heavy neutrophilic infiltration of their interstitial spaces and pulmonary capillary congestion (Fig. 2).

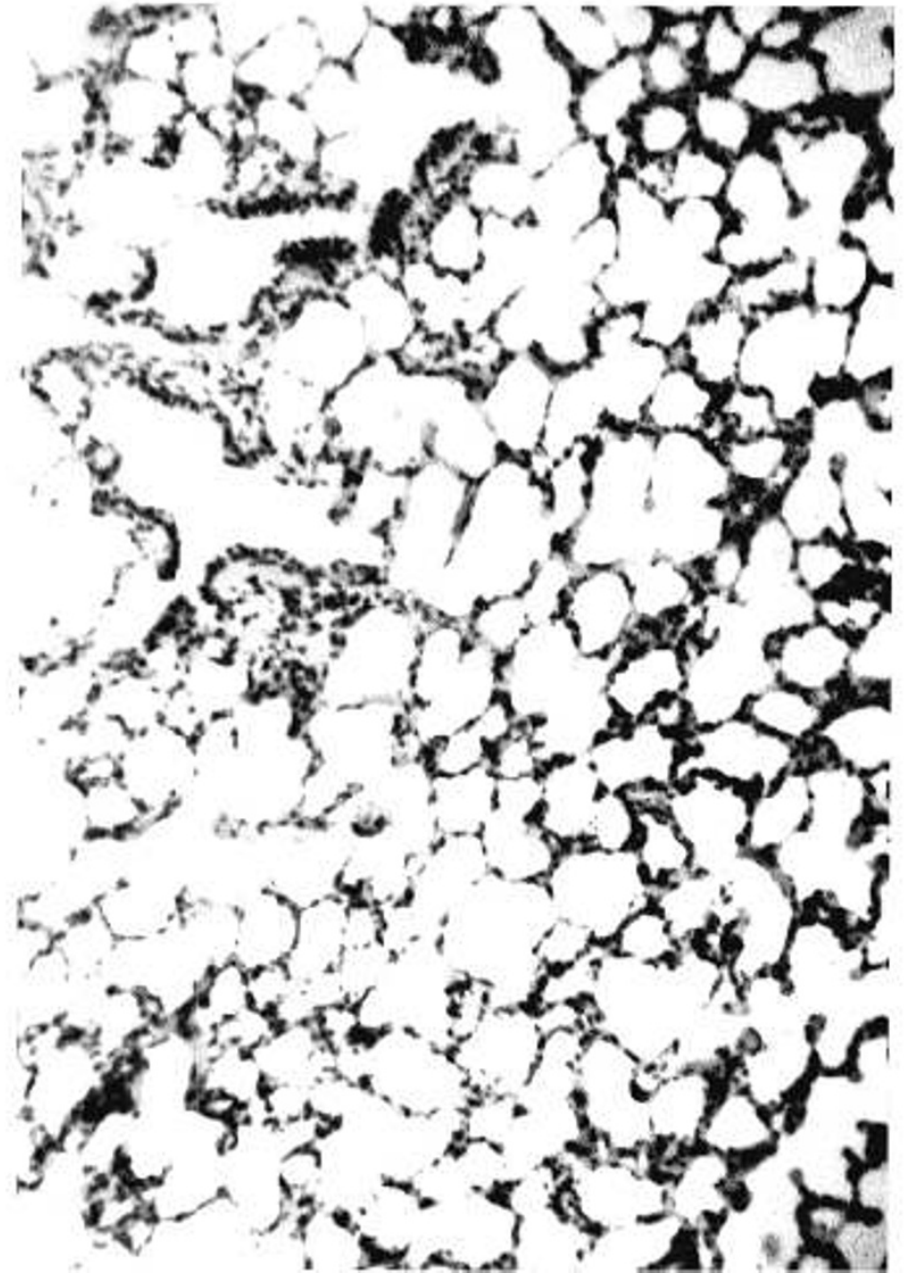

Fig. 1. Neonatal lamb lung. This lung from a neonatal lamb infused with only saline shows normal alveolar septae with occasional neutrophils in the interstitial space.

Aggregation studies. Attempts to induce aggregation of PMNs with increasing concentrations of GBS-TCA in PBS were unsuccessful. However, prompt aggregation occurred when GBS-TCA was preincubated in whole serum. Figure 3 depicts the in vitro aggregation patterns observed with adult PMNs. The first curve, after an initial dilution effect, shows typical biphasic aggregationdeaggregation following exposure of adult PMNs to GBS-TCA in human serum. Biphasic PMN aggregation was not seen with GBS-TCA preincubated in PBS or serum without GBS-TCA (curves 2 and 3).

PMN aggregation, induced by GBS-TCA at various concentrations and following preincubation in human serum, is depicted in Table 1 . No aggregation was observed at 0.01 or $0.05 \mathrm{mg}$ GBS-TCA $/ \mathrm{ml}$ of serum. Aggregation occurred at $0.1,0.5$, and $1.0 \mathrm{mg} / \mathrm{ml}$ concentrations (Table 2). Aggregation did not occur with GBS-TCA in PBS with PMNs from eight different adults. However, a significant increase in aggregation was observed when GBS-TCA, preincubated in serum, was added to PMNs. Serum alone (Fig. 3) induced no aggregation (DT $3.56 \pm 1.59 \mathrm{SD}, n=$ 9). Addition of concentrations of TCA 2.5 to $25 \%$ to serum induced precipitation of serum proteins. However, after centrifugation supernatants from these preparations did not aggregate PMNs; TCA (2.5 to 25\%) in PBS also did not aggregate PMNs.

PMNs isolated from three human cord blood specimens were tested. Incubation of GBS-TCA in human serum at a concentration of $1.0 \mathrm{mg}$ extract $/ \mathrm{ml}$ serum resulted in the typical newborn pattern of irreversible aggregation $(\Delta \mathrm{T}: 7,12$, and 14\%). The mean increase in light transmission $(11 \% \pm 3.61 \mathrm{SD})$ was similar to the response of adult PMNs. 


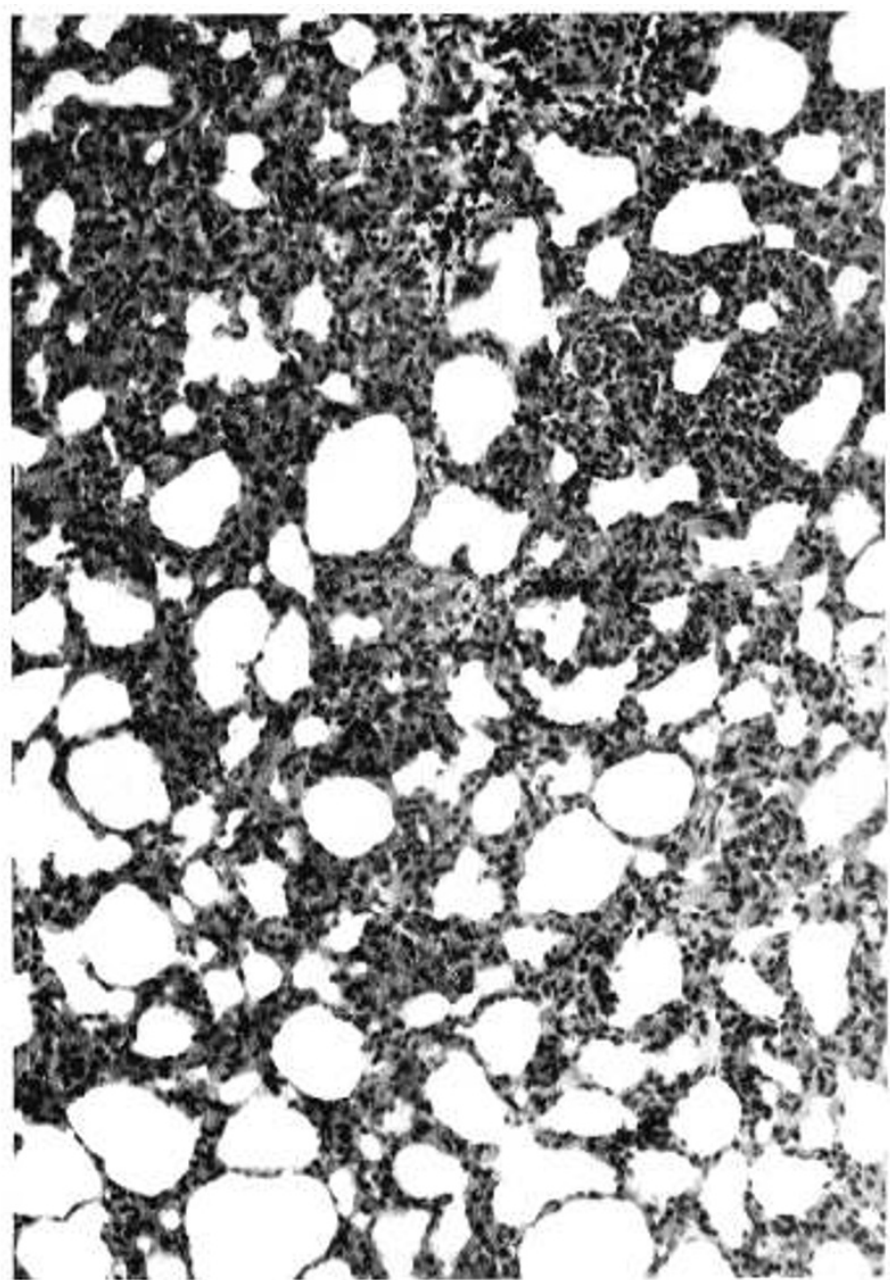

Fig. 2. Neonatal lamb lung after infusion of GBS-TCA extract. The alveolar septae are greatly widened with a neutrophilic infiltration of the interstitial space.

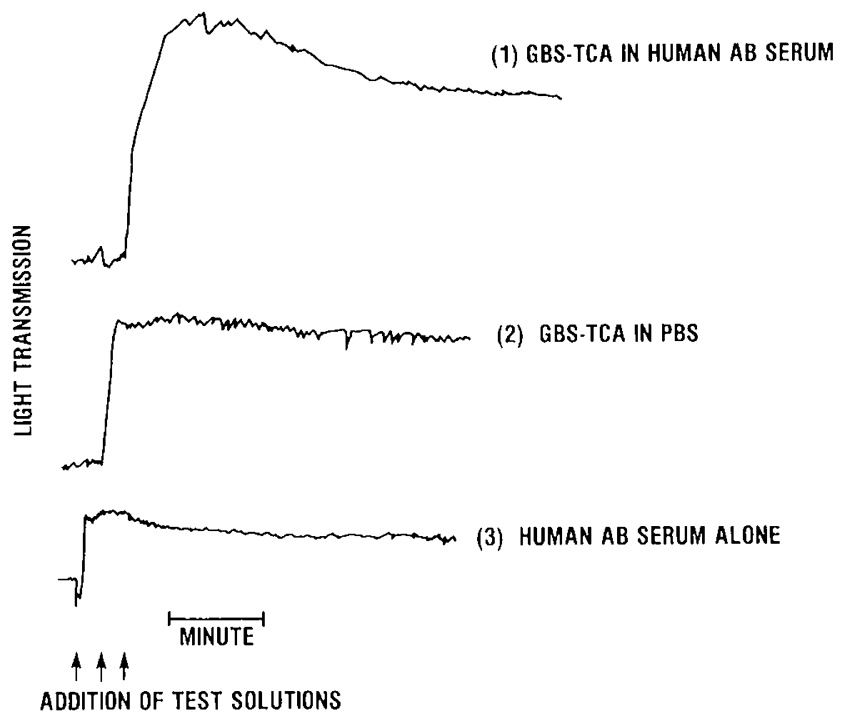

Fig. 3. Neutrophil aggregation with group B streptococcal extract. After an initial dilutional effect, the change in light transmission (representing aggregation) is noted after the test solution is added. GBS-TCA in serum caused typical aggregation-deaggregation pattern $(I)$. This was not seen with GBS-TCA in PBS (2) or human serum alone (3). Concentration extract $1.0 \mathrm{mg} / \mathrm{ml}$.
Table 1. GBS-TCA incubated in serum: dose response $(\bar{x} \pm S D)$

\begin{tabular}{cc}
\hline $\begin{array}{c}\text { GBS-TCA concentration } \\
\text { in serum }(\mathrm{mg} / \mathrm{ml})\end{array}$ & $\begin{array}{c}\text { Change in light } \\
\text { transmission }(\Delta \mathrm{T})\end{array}$ \\
\hline 0.01 & No biphasic aggregation \\
0.05 & No biphasic aggregation \\
0.1 & $7.48 \% \pm 2.2$ \\
0.5 & $10.87 \% \pm 2.86$ \\
1.0 & $12.34 \% \pm 2.83$ \\
\hline
\end{tabular}

Table 2. GBS-TCA in vitro neutrophil aggregation*

\begin{tabular}{lcc}
\hline & \multicolumn{2}{c}{$\%$ change in light transmission $(\Delta \mathrm{T})$} \\
\cline { 2 - 3 } & GBS-TCA in serum & GBS-TCA in PBS \\
\hline 13.7 & 3.1 \\
17.9 & 4.2 \\
11.3 & 4.7 \\
12.6 & 0.0 \\
& 10.0 & 0.0 \\
& 8.4 & 0.0 \\
& 11.6 & 4.7 \\
& 13.2 & 3.2 \\
Mean & 12.34 & 2.49 \\
SD & 2.83 & 2.14 \\
Paired test & $p<0.001$ & \\
\hline
\end{tabular}

${ }^{*}$ GBS-TCA - final concentration $-1.0 \mathrm{mg} / \mathrm{ml}$

Subsequent studies were conducted with a new serum source, with better attention toward the preservation of complement. With this serum $0.1 \mathrm{mg} / \mathrm{ml}$ of extract yielded good aggregation curves so this concentration was used in contrast to the initial studies with $1 \mathrm{mg} / \mathrm{ml}$. Figure 4 depicts the characteristic biphasic aggregation (curve I) observed with adult neutrophils exposed to GBS-TCA in human serum. The second curve is representative of the significant reduction in aggregation with GBS immune globulin as compared to control GBS-TCA in serum (Table 3). In contrast (curve 3), when Sandoglobulin lot 2.370.069.0 was used with GBS-TCA, augmented irreversible aggregation of PMNs occurred (mean $\Delta \mathrm{T} 11.63 \pm 2.56 \mathrm{SD}$ versus $11.75 \pm 2.42$ SD control, $n=4$, NS).

Further studies examined whether heat treatment of serum altered PMN aggregation. The curve in Figure 4 depicts the inhibition of aggregation following heat inactivation of serum before incubation with GBS-TCA. However, when GBS-TCA was first incubated in serum prior to heating $\left(56^{\circ} \mathrm{C}\right.$ for $\left.30 \mathrm{~min}\right)$, aggregation was unchanged as compared to controls (Table 4). Twenty mM EGTA also significantly decreased aggregation (mean $\Delta \mathrm{T} 6.25 \pm 3.2$ versus $15.6 \pm 4.9$ control, $p=0.008$ ).

\section{DISCUSSION}

Early onset neonatal GBS sepsis often results in shock, pneumonia, and neutropenia in afflicted infants. Several studies demonstrate that sterile cell-free extracts of GBS produce similar effects when infused into lambs and piglets $(2,3,6,7)$. In this study, a TCA extract of GBS strain 878 (type III) induced reductions in white blood cell counts and a marked accumulation of PMNs in the pulmonary interstitia of newborn lambs. The extract also aggregated human PMNs in vitro in the presence of serum. If intravascular PMN aggregates were formed during human neonatal GBS bacteremia, trapping of the aggregates might occur in the pulmonary microvasculature. A secondary inflammatory response might enhance local pulmonary injury as has been described in adult respiratory distress syndrome and in patients on hemodialysis $(8-10)$. The removal of PMNs from the circulation by this mechanism might deplete PMN reserves 


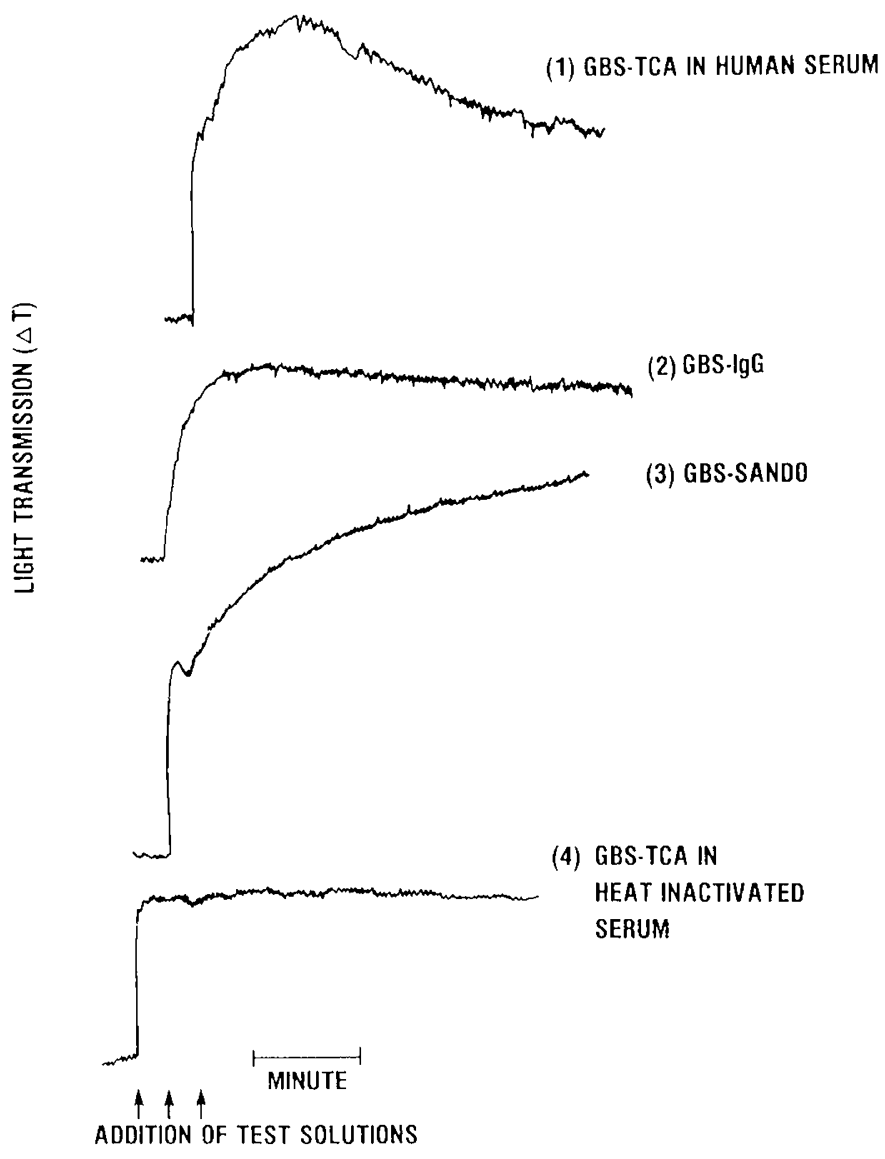

Fig. 4. Studies of inhibition of neutrophil aggregation by group B streptococcal extract. The typical aggregation-deaggregation curve is seen with GBS-TCA in serum (1). If the GBS-TCA was first exposed to IgG (GBS immune globulin) the resultant preparation did not cause aggregation (2). Mixing of GBS-TCA with standard Sandoglobulin resulted in augmented irreversible aggregation (3). Heat inactivation of serum prior to the addition of GBS-TCA also prevented neutrophil aggregation (4). Concentration extract $0.1 \mathrm{mg} / \mathrm{ml}$.

Table 3. GBS-TCA-preincubated with $10 \%$ GBS immune globulin in vitro neutrophil aggregation*

\begin{tabular}{lcc}
\hline & \multicolumn{2}{c}{$\%$ change in light transmission $(\Delta \mathrm{T})$} \\
\cline { 2 - 3 } & GBS-TCA in serum & GBS-IgG \\
\hline 17.0 & 5.0 \\
16.5 & 4.5 \\
10.5 & 3.0 \\
14.0 & 8.0 \\
15.0 & 5.0 \\
& 16.5 & 7.0 \\
& 14.92 & \\
Mcan & 2.44 & 5.42 \\
SD & $p=0.0002$ & 1.80 \\
Paired $t$ test & & \\
\hline
\end{tabular}

* GBS-TCA - final concentration $-0.1 \mathrm{mg} / \mathrm{ml}$.

(11) in the neonate whose marrow progenitors already may have limited potential to respond (12). Human neonatal PMNs aggregate differently in vitro than adult PMNs. In previous reports a pattern of irreversible aggregation has been seen when neonatal PMNs were exposed to chemotactic peptides such as FMLP (13, 14). When neonatal PMNs irreversibly aggregate, the effect may not be transient. Aggregates may become entrapped in the pulmonary microvasculature, disintegrate, and release toxic products.
Table 4. GBS-TCA in heat-inactivated serum neutrophil aggregation*

\begin{tabular}{lcccc}
\hline & \multicolumn{3}{c}{$\%$ changes in light transmission $(\Delta \mathrm{T})$} \\
\cline { 2 - 5 } & No heat & $\begin{array}{c}\text { Before } \\
\text { extract } \dagger\end{array}$ & No heat & $\begin{array}{c}\text { After } \\
\text { extract }\end{array}$ \\
\hline & 12.5 & 6.5 & 17.5 & 16 \\
& 13.5 & 3.0 & 16. & 16 \\
& 10.0 & 1.5 & 9.5 & 15 \\
Mean & 7.0 & 2.0 & 14.5 & 10 \\
SD & 10.75 & 3.25 & 14.38 & 14.25 \\
Paired $t$ test & 2.90 & 2.25 & 3.47 & 2.87 \\
\hline
\end{tabular}

* GBS-TCA - final concentration $-0.1 \mathrm{mg} / \mathrm{ml}$.

$\uparrow$ Heated at $56^{\circ} \mathrm{C}$ for $30 \mathrm{~min}$.

GBS-TCA did not directly aggregate human PMNs in vitro. However, the presence of fresh serum was a potent stimulus for PMN aggregation. Serum alone did not induce aggregation. TCA did not aggregate neutrophils or activate serum to induce neutrophil aggregation. The initial studies were done with a single serum source. As there had been frequent freeze-thawing of that serum, another lot of serum was obtained and utilized a manner to preserve complement. The new serum induced comparable aggregation curves at 10 -fold lower extract concentrations suggesting that complement activation and $\mathrm{C} 5 \mathrm{a}$ might be responsible for aggregation. It is known that complement, specifically C5a, will aggregate PMNs in vitro (15-17). C5a appears to be stable after heating at $56^{\circ} \mathrm{C}$ for $30 \mathrm{~min}$, whereas whole complement is inactivated (5). Heat inactivation of serum, prior to the addition of GBS-TCA, abrogated the aggregation of PMNs. If GBS-TCA were incubated in serum containing complement and then the mixture were heated a biphasic aggregation-deaggregation PMN curve was seen. Therefore, heat labile complement may be converted to heat stable C5a in the presence of GBS-TCA. Activation of complement by GBS may play a role in the aggregation of PMNs in vivo and contribute to the localization of PMNs in the pulmonary interstitium.

A deficiency of GBS antibody increases the risk of serious neonatal GBS infections. Conversely adequate amounts of circulating GBS antibody may enhance survival in septic premature infants (18). The role of antibody in preventing or improving survival in GBS disease has been thought to be secondary to its ability to enhance phagocytosis and killing of bacteria $(19,20)$. In this study GBS immune globulin appeared to interupt PMN aggregation in vitro. In contrast, a standard immunoglobulin preparation augmented aggregation. It is possible that hyperimmune GBS globulin may limit pulmonary damage caused by PMN aggregates. Further work needs to be done to better understand the relevance of these observations.

\section{REFERENCFS}

1. Hemming VG, McCloskey DW, Hill HR 1976 Pneumonia in the neonate associated with group B streptococcal septicemia. Am J Dis Child 130:12311233

2. Hemming VG, O'Brien WF, Fischer GW, Golden SM, Noble SF 1984 Studies of short-term pulmonary and peripheral vascular responses induced in oophorectomized sheep by the infusion of a group B streptococcal extract. Pediatr Res 18:266-269

3. O'Brien WF, Golden SM, Bibro MC, Charkobardi PK, Davis SE, Hemming VG 1985 Short-1erm responses in neonatal lambs after infusion of group $B$ streptococcal extract. Obstet Gynecol 65:802-806

4. Boyum A 1968 Isolation of mononuclear cells and granulocyles from human blood. Isolation of monomononuclear cells by one centrifugation and of granulocytes by combining centrifugation and sedimentation at $1 \mathrm{~g}$. Scand $\mathbf{J}$ Clin Lab Invest 97(suppl):77-89

5. Craddock PR, Hammerschmidt DE, White JG, Dalmasso AP, Jacob HS 1977 Complement (C5a) induced granulocyte aggregation in vitro. J Clin Invest 60:260-264

6. Hellerquist CG, Rojas J, Green RS, Sell S, Sundell H, Stahlman MT 1981 Studies on group $\mathrm{B}$ hemolytic streptococcus. I. Isolation and partial charac- 
terization of an extracellular toxin. Pediatr Res 15:892-898

7. Rojas J, Larsson LE, Ogletree ML, Brigham KL, Stahlman MT 1983 Effects of cyclooxygenase inhibition on the response to group B streptococcal toxin in sheep. Pediatr Res 17:107-110

8. Zimmerman GA, Renzetti AD, Hill HR 1983 Functional and metabolic activity of granulocytes from patients with adult respiratory syndrome. Am Rev Respir Dis 127:290-300

9. Hammerschmidt DE 1983 Leukocytes in lung injury. Chest 5:165-205

10. Jacob HS, Craddock PR, Hammerschmidt DE, Moldow CF 1980 Complement-induced granulocyte aggregation: an unsuspected mechanism of discasc. N Engl J Med 302:789-794

11. Christensen RD, Rothstein G 1980 Exhaustion of mature marrow neutrophils in neonates with sepsis. J Pediatr 96:316-318

12. Christensen RD, Hill HR, Rothstein G 1983 Granulocyte stem cell (CFUC) proliferation in experimental group B streptococcal sepsis. Pediatr Res $17: 278-280$

13. Mease AD, Burgess DP, Thomas PJ 1981 Irreversible neutrophil aggregation: a mechanism of decreased newborn neutrophil chemotactic response. Am J Pathol 104:98-102

14. Olson TA, Ruymann FB, Cook BA, Durgess DP, Hensen SA, Thomas PJ 1983
Newborn polymorphonuclear leukocyte aggregation: a study of physical properties and ultrastracture using chemotactic peptides. Pediatr Res 17:993-997

15. Becker EL, Showell HJ 1974 The ability of chemotactic factors to induce lysosomal enzyme release. II. The mechanism of release. J Immunol 112:2055-2062

16. Vallota EH, Müller-Eberhard HJ 1973 Formation of C3a and C5a anaphylatoxins in whole human serum after inhibition of the anaphylatoxin inactivator. J Exp Med 137:1109-1123

17. O'Flaherty JT, Showell HJ, Becker EL, Ward PA 1978 Substances which aggregate neutrophils. Am J Pathol 92:155-166

18. Sidiropoulos D, Bohme V von Muralt G, Morell A, Barandun A 198 Immunoglobulinsubstitution bei der behandlung der nconatalen sepsis. Schweiz Med Wochenschr 111:1649-1655

19. Edwards MS, Nicholson-Weller A, Baker CJ, Kasper DL 1980 The role of specific antibody in alternative complement pathway-mediated opsonophagocyosis of type III, group B streptococcus. J Exp Med 151:1275-1287

20. Shigeoka AO, Hall RT, Hemming VG, Allred CD, Hill HR 1978 Role of antibody and complement in opsonization of group $\mathrm{B}$ streptococci. Infect Immun 21:34-40 